\title{
Protective Effects of Aqueous Extract of Sempervivum tectorum L (Crassulaceae) on Aluminium-Induced Oxidative Stress in Rat Blood
}

\author{
Muselin Florin ${ }^{1}$, Trif Alexandra ${ }^{1^{*}}$, Stana Loredana Gabriela ${ }^{2}$, Cristina Teodor \\ Romeo $^{3}$, Grăvilă Corina ${ }^{4}$, Măcinic loan ${ }^{1}$ and Dumitrescu Eugenia ${ }^{3}$ \\ ${ }^{1}$ USAMVB Faculty of Veterinary Medicine, Department of Toxicology, Vegetal Biology and Medicinal Plants, ${ }^{2}$ University of \\ Medicine and Pharmacy "Victor Babeș", ${ }^{3}$ USAMVB Faculty of Veterinary Medicine, Department of Pharmacology, ${ }^{4}$ USAMVB \\ Faculty of Zootehny and Biotechnology, Department of Biochemistry, Timișoara, România
}

*For correspondence: Email: al trif@yahoo.com; Tel: +40256277076,

\begin{abstract}
Purpose: To examine the effect of Sempervivum tectorum aqueous extract, as infusion, on some biomarkers of oxidative stress induced by aluminium exposure in Wistar albino rat.

Methods: The rats were randomly divided into five groups and treated daily for 3 months as follows: control received tap water; the $2^{\text {nd }}$ group was given $1 \mathrm{mg} / \mathrm{L}$ aluminium as aluminium sulphate $(A S)$ in drinking water daily; group 3, a combination of $1 \mathrm{mg} / \mathrm{L} \mathrm{AS}$ and Sempervivum tectorum extract daily; the fourth group, Sempervivum tectorum extract daily; and fifth group $1 \mathrm{mg} / \mathrm{L}$ AS for three months and thereafter Sempervivum tectorum extract for one month.

Results: Aluminium (Al) exposure increased, compared to control group, the level of blood Al (293.64 $\%, p<0.0001$ ), serum superoxide dismutase (SOD, $14.84 \%, p>0.05)$, glutathione peroxidase (G-PX, $31.25 \%, p<0.001$ ) and thiobarbituric reactive substances (TBARS, $21.37 \%, p<0.001$ ) but significantly decreased catalase (CAT, $49.59 \%, p<0.001)$, glutathione (GSH, $13.49 \%, p<0.001$ ) and glutathione reductase (GSH-r, $23.08 \%, p<0.0001)$ levels. These results indicate that Al-induced oxidative stress in the rats. Following administration of Sempervivum tectorum extract, the levels of the oxidative stress biomarkers were restored to normal, indicating good antioxidant properties of the extract. Al blood level was also significantly reduced by $33.45 \%(p<0.001)$ in rats exposed to the extract. Rat body weight was not significantly $(p>0.05)$ affected by the extract.

Conclusion: S. tectorum extract possesses antioxidant activity against free radicals produced in blood as a result of aluminium exposure.
\end{abstract}

Keywords: Aluminium exposure, Sempervivum tectorum, Biomarkers, Free radicals, Oxidative stress.

Tropical Journal of Pharmaceutical Research is indexed by Science Citation Index (SciSearch), Scopus, International Pharmaceutical Abstract, Chemical Abstracts, Embase, Index Copernicus, EBSCO, African Index Medicus, JournalSeek, Journal Citation Reports/Science Edition, Directory of Open Access Journals (DOAJ), African Journal Online, Bioline International, Open-J-Gate and Pharmacy Abstracts

\section{INTRODUCTION}

Sempervivum tectorum (Crassulaceae family), known as houseleek, is an evergreen plant with perennial root, crowned with imbricated fleshy leaves, which are smooth on both sides and ciliated at the margin, with the stem rising from the center of the tuft of leaves and terminated with a cymose corymb flowers [1]. It has been used for many years in the treatment of ear inflammation [1, 2], insect bites, burns and ulcer [2] having also an antinociceptive activity [3]. The extract from this plant contains approximately 20 different flavones and flavonol mono- and diglycosides [2-4]. The main flavonoid glycoside is kaempferol [4-6]. 
The aim of the present work was to determine if the aqueous extract of Sempervium tectorum can offer protection against the oxidative stress induced by aluminium exposure in rats.

\section{EXPERIMENTAL}

\section{Animals}

Thirty five adult Wistar albino rats, (six months old), were purchased from the Animal House of University of Medicine and Pharmacy "Victor Babeş" Timisoara, Romania. The rats were housed in plastic cages, at constant room temperature of $23 \pm 2{ }^{8} \mathrm{C}, 12 \mathrm{~h}$ light/dark cycle and fed ad libitum with standard diet. They were kept in the cages for one week to acclimatize before the start of the experiment, and handled in accordance with Directive 2010/63/EU on the handling of animals used for scientific purposes [7]. The experiment was approved by the Ethical Committee of Banat's University of Agricultural Science and Veterinary Medicine, Timisoara (no. 3558/05.06.2012).

\section{Plant material}

Sempervivum tectorum (St), identified by $\mathrm{Dr}$. Muselin Florin (Head, Department of Vegetal Biology and Medicinal Plants, Faculty of Veterinary Medicine), was collected during Spring/Summer seasons of 2012 from the field of Timis County, Romania and was compared for identification with a herbarium specimen deposited in the Department of Vegetal Biology and Medicinal Plants, Faculty of Veterinary Medicine Timisoara, Romania (voucher no. 112). The fresh leaves were removed from the rosette and roots, washed and dried in oven at $50{ }^{\circ} \mathrm{C}$, to a constant weight. The extract was performed from $S$. tectorum dry leaves with $0.4 \mathrm{~mm}$ particle size in tap water (the ratio $w / v \quad 0.8 / 10$ ), in Erlenmeyer flasks. The mixture was heated at 90 ${ }^{0} \mathrm{C}$ for $10 \mathrm{~min}$ in water bath and after, twice filtered [8]. The level of aluminium in the plant,material was determined by atomic absorption spectroscopy.

\section{Animal grouping}

The rats were randomly divided into five groups treated as shown: Group I (C, control i.e., tap water containing $50 \mu \mathrm{g} / \mathrm{L} \mathrm{Al}$ ); Group II (Al) - 1 $\mathrm{mg} / \mathrm{L} \mathrm{Al}$ as aluminium sulphate (AS); Group III $(1 \mathrm{mg} / \mathrm{L}$ AS $+8 \%$ S. tectorum extract; Group IV (8\% S. tectorum).; Group V (1mg/L AS for three months and thereafter, $8 \%$ S. tectorum for one month. At the end of the experiment, three months for groups I to IV and four months for group $V$, the rats were weighed and euthanatized by exsanguinations after administering ketamine $50 \mathrm{mg} / \mathrm{kg}$ b.w. anesthesia (10\% Ketaminol, Intervet International BV, Boxmeer, Holland) and blood was collected in $\mathrm{BD}$ vacutainers - Plasma Heparinized (LH 102 IU) BD Vacutainer (ref no. 367885) for plasma samples and Serum Plain BD Vacutainer (ref. no. 367837), without anticoagulant for serum samples.

\section{Aluminium analysis and estimation of oxidative stress biomarkers}

Aluminium was determined by atomic absorption spectroscopy at $309.3 \mathrm{~nm}$ wavelength, after nitric acid digestion $(1 \mathrm{~mL}$ sample and $10 \mathrm{~mL}$ nitric acid in digestion flasks for $20 \mathrm{~min}$ at $120^{\circ} \mathrm{C}, 600$ $\mathrm{W}$ in CEM MARS X5 microwave digestion oven) using a Shimadzu AA6650 spectrometer (Shimadzu, Kyoto, Japan) with graphite furnace (pyrolytic graphite tube) by the method of Gitelman and Alderman [9]. Aluminium standard solution - $\mathrm{Al}\left(\mathrm{NO}_{3}\right)_{3}$ in $0.5 \mathrm{~mol} / \mathrm{L}$ nitric acid $(1000$ $\mathrm{mg} / \mathrm{L}$ Al, Merck KGaA, Darmstadt, Germany). Detection limit for Al was $0.2 \mu \mathrm{g} / \mathrm{L}$. The blood samples, colected in $B D$ vacutainers with lithium heparin (ref no. 367885), were centrifuged for 10 $\mathrm{min}$ at $4000 \mathrm{rpm}$, plasma separated and the packed erythrocytes washed 3 times with normal saline to obtain the hemolysate. Reduced GSH was assessed in the hemolysate according to the method of Beutler et al [10] based on the reduction of 5,5'-dithiobis (2-nitrobenzoic acid) (DTNB) with glutathione to produce a yellow compound with maximum absorbance at $412 \mathrm{~nm}$. The antioxidant enzyme G-Px in hemolysate was evaluated according to the method of Paglia and Valentine [11]. G-Px catalyzes the oxidation of GSH by $\mathrm{NADP}^{+}$. In the presence of GSH-r and $\mathrm{NADPH}$, the oxidized glutathione (GSSG) is immediately converted to the reduced form (GSH) with concomitant oxidation of NADPH to $\mathrm{NADP}^{+}$. The decrease in absorbance was measured at $340 \mathrm{~nm}$. GSH-r activity in hemolysate was assayed using the method of Beutler [12]. GSH-r catalyzes the reduction of GSSG in the presence of NADPH, which is oxidized to NADP ${ }^{+}$. The decrease in absorbance was measured at $340 \mathrm{~nm}$.

Catalase activity in blood samples was assayed according to the method of Sinha [13] based on the reduction of dichromate in acetic acid to chromic acetate when heated in the presence of hydrogen peroxide, the green colored produced compound has the maximum absorbance at 570 $\mathrm{nm}$. SOD activity in serum was assayed by a method of Beuchamp and Fridovich [14]. The principles of SOD assay was based on the inhibition of NTB (nitroblue tetrazolium) reduction by superoxide radicals to blue colored formazan 
with maximum absorbance at $560 \mathrm{~nm}$. TBARS was measured according to method of Ohkava modified by Turgut et al [15]. Hemoglobin ( $\mathrm{Hb})$ was determined by the cyanomethemoglobin method, using the Drabkin reagent (SigmaAldrich, Saint Louis, Missouri, USA). All measurements were made with a Shimadzu UVmini 1240 spectrophotometer (Shimadzu, Kyoto, Japan).

\section{Statistical analysis}

The results are expressed as mean \pm SEM. For the evaluation of differences between groups, one-way ANOVA with Bonferroni's correction was used, with statistical difference set at $p<$ 0.05. The statistical software used was GraphPad Prism 5.0 for Windows (GraphPad Software, San Diego, USA).

\section{RESULTS}

The mean aluminium content of the plant was $4.736 \mu \mathrm{g} / \mathrm{g}$ while it was $157 \mu \mathrm{g} / \mathrm{L}$ in the aqueous extract.

\section{Body weight, blood aluminium levels and hemoglobin}

The body weight was slightly increased in all experimental groups compared to control, but the differences were not significant $(p>0.05)$.

Blood Al level was significantly $(p<0.001)$ increased in rats exposed to AS compared to control (293.64 \%). When the rats were exposed to AS in combination with $S$. tectorum extract, Al level decreased significantly $(p<0.001)$ comparative to the group given AS alone (33.45 $\%)$ but was still increased comparative to control (161.95\%, $p<0.001)$. In rats exposed to extract alone, Al level was lower than in control group but the differences were not significant $(10.18 \%$, $p>0.05)$. The administration of the extract during one month after AS exposure was stopped did not significantly reduce blood Al level comparative to Al group (7.8 1\%, p>0.05), remaining still significantly $(p<0.001)$ higher than control $(262.74 \%)$. Compared to $\mathrm{Al}+\mathrm{St}$ group, the blood Al level was significantly ( $p<$ $0.05)$ higher (38.47 \%). The differences regarding $\mathrm{Hb}$ levels were not significant $(p>$ 0.05).

\section{Oxidative Stress Biomarkers}

GSH level (Fig 1) decreased significantly ( $p<$ 0.01 ) in the Al group compared to control (13.49 $\%)$ and increased when the rats were exposed only to extract (55.63\%, $p<0.01)$. Administration of the extract together with AS restored the GSH level but it still remained lower than in control group (3.94\%, $p>0.05)$. When the extract was administered one month after the AS administration was stopped the GSH level was significantly increased $(p<0.05)$ relative to the Al group (14.88 \%) but was not significantly $(p>0.05)$ different from the Al+St $(3.47 \%)$ and control $(0.61 \%)$ groups.

A significant decrease $(p<0.0001)$ in the GSH-r level in rats exposed to AS, compared to control $(23.08 \%)$ was seen (Fig 1). When AS was administered together with extract GSH-r increased but still remained significantly $(p<$ $0.01)$ lower than in control $(12.06 \%)$. The same profile was seen when the extract was administered after AS exposure was stopped (7.90\%, $p>0.05)$. Compared to Al group, GSH-r levels were higher in Al+St (14.32\%, $p<0.01)$, St $(40.28 \%, p<0.001)$ and Al+1mSt (19.73\%, $p$ $<0.001)$ groups. Nosignificant $(p>0.05)$ differences in GSR-r were seen between control and St group $(7.90 \%)$ and also between $\mathrm{Al}+\mathrm{St}$ and $\mathrm{Al}+1 \mathrm{mSt}(4.37 \%)$.

G-Px increased significantly $(p<0.001)$ in rats exposed to AS (31.25\%) but the decrease when AS was administered together with extract, was not significant. Not significant $(p>0.05)$ differences in G-Px level were observed between the group exposed to extract and control group (11.64 \%). Administration of the extract for a month after the AS intake was stopped, resulted in G-Px recovery to a level not significantly $(p>$ $0.05)$ different from control $(2.44 \%)$. G-Px levels were lower in $\mathrm{Al}+\mathrm{St}(22.30 \%, p<0.001)$, St $(32.68 \%, p<0.001)$ and $\mathrm{Al}+1 \mathrm{mSt}(21.95 \%, p<$

Table 1: Body weight, Al blood levels and hemoglobin (mean \pm SEM) in rats exposed to aluminium and Sempervivum tectorum extract

\begin{tabular}{llllll}
\hline Parameter & C & Al & Al + extract & St & $\begin{array}{l}\text { Al + extract } \\
\text { for 1 month }\end{array}$ \\
\hline Body weight $(\mathrm{g})$ & $380.0 \pm 14.61$ & $406.7 \pm 11.16^{\mathrm{a}}$ & $383.3 \pm 10.85^{\mathrm{a}}$ & $403.3 \pm 15.2^{\mathrm{a}}$ & $403.4 \pm 8.81^{\mathrm{a}}$ \\
\hline $\mathrm{Al} \mathrm{blood} \mathrm{level}(\mu \mathrm{g} / \mathrm{L})$ & $9.158 \pm 0.56$ & $36.05 \pm 2.77^{\mathrm{D}}$ & $23.99 \pm 1.46^{\mathrm{b}, \mathrm{c}}$ & $8.225 \pm 0.56^{\mathrm{a}}$ & $33.22 \pm 2,19^{\mathrm{b}, \mathrm{d}}$ \\
\hline $\mathrm{Hb}(\mathrm{g} / \mathrm{L})$ & $2.26 \pm 0.07$ & $1.88 \pm 0.04$ & $2.27 \pm 0.22$ & $2.72 \pm 0.30$ & $2.11 \pm 0.02$ \\
\hline
\end{tabular}

Comparison with control group: ${ }^{a}=$ not significant; ${ }^{b} \mathrm{p}<0.001$; comparison with Al group: ${ }^{c} \mathrm{p}<0.01$; comparison between $\mathrm{Al}+\mathrm{S}$ and $\mathrm{Al}+$ extract for 1 month: ${ }^{\mathrm{d}} \mathrm{p}<0.05$ 

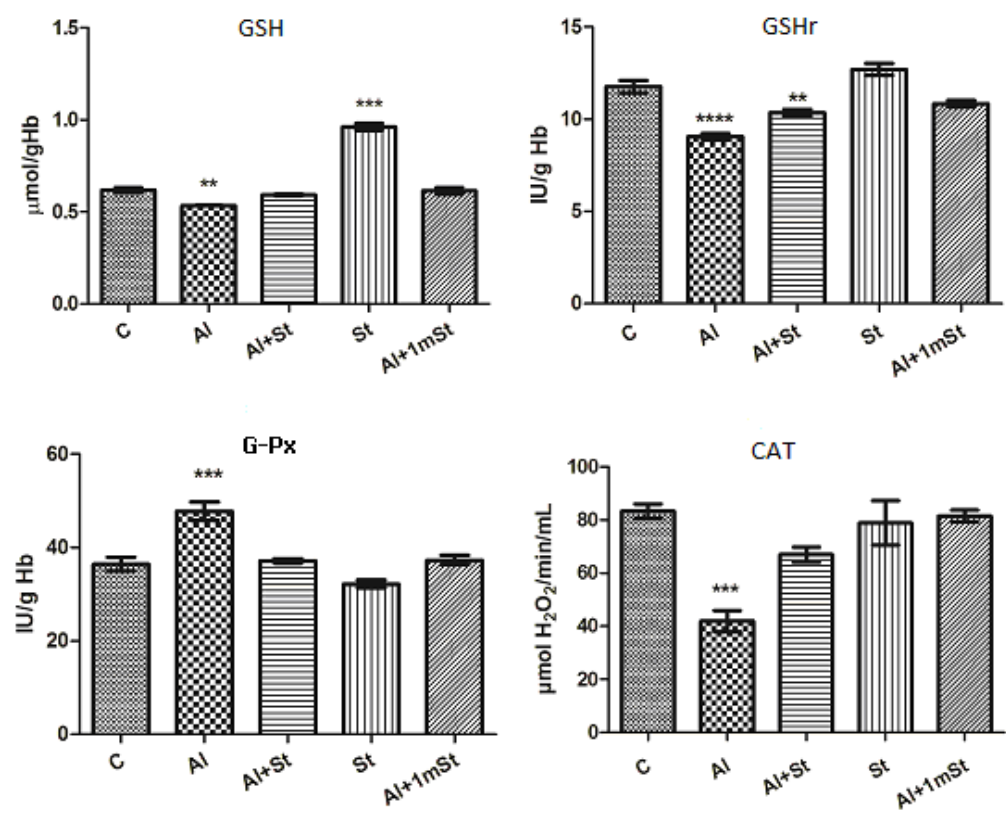

Fig 1: GSH, GSH-r, G-px and CAT levels in rats exposed to aluminium and Sempervivum tectorum extract; ${ }^{* *} p<$ $0.01,{ }^{* * *} p<0.001,{ }^{* * *} p<0.0001$ compared with control

SOD

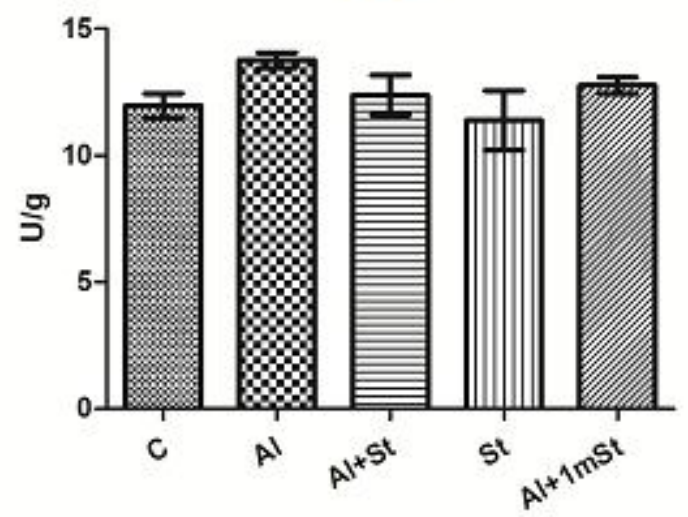

TBARS

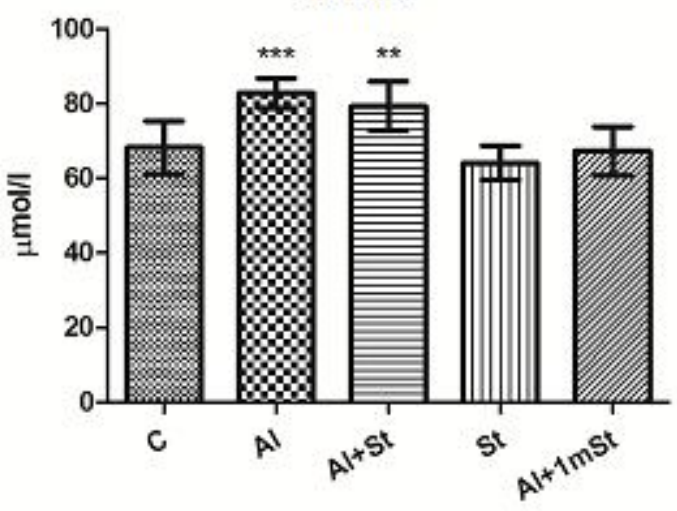

Fig 2: SOD and TBARS levels in rats exposed to aluminium and Sempervivum tectorum extract; ** $p<$ $0.01{ }^{* * *} p<0.001$ compared with control

0.001) groups compared to $\mathrm{Al}$ group. G-Px activity was not significantly different in $\mathrm{Al}+1 \mathrm{mSt}$ group compared to $\mathrm{Al}+\mathrm{St}$ group $(0.45 \%, p>$ 0.05).

CAT activity was reduced, significantly ( $p<$ $0.001)$ in group exposed to AS (49.59 \%) but not significantly $(p>0.05)$ when AS was administered together with extract (19.60\%). The activity was recovered in the presence of the extract when it was administered one month after AS administration was stopped even though it still remained lower than control $(2.18 \%, p>$ $0.05)$. This activity was significantly higher in Al+St $(59.50 \%, p<0.001)$, St $(87.97 \%, p<$ $0.001)$ and $\mathrm{Al}+1 \mathrm{mSt}(94.06 \%, p<0.001)$ groups compared to Al group.
In all experimental groups, the difference in SOD levels (Fig 2$)$ was not significant $(p>0.05)$ when compared to control.

TBARS values (Fig 2) significantly $(p<0.001)$ increased in Al group compared to control (21.37 $\%)$. The extract reduced TBARS level when was administered together with $A S$, but the values were still significantly $(p<0.01)$ increased compared to control (16.28\%). Administration of the extract after AS exposure was stopped, significantly $(p<0.001)$ decreased the TBARS level, being even lower than control.

\section{DISCUSSION}

The release of free iron ions from biological complexes by aluminium can catalyze hydrogen peroxide decomposition to hydroxyl radical via 
Fenton's reaction, initiating cellular damage [1618]. Aluminium is able to inhibit NADPHgenerating enzymes such as glucose-6phosphate dehydrogenase and NADP-isocitrate dehydrogenase, and because the reduced NADP is a co-enzyme for GSH regeneration, the decreased GSH level could be due to insufficient supply of NADPH [19]. We observed a significant decrease in the levels of erythrocyte $\mathrm{GSH}$ in groups exposed to AS, which were restored in all groups by extract administration. Moreover, the activities of erythrocyte antioxidant enzymes SOD and G-Px were increased in rats exposed to AS compared but this was reversed when AS was administered together with $S$. tectorum. SOD is an important antioxidant enzyme neutralizes superoxide anion. This increase of SOD might be an adaptative response.

G-Px plays a significant role in the peroxyl scavenging mechanism and in the maintenance of the integrity of erythrocyte cell membrane [20]. The increase of GSH-Px activity could be due to its induction to counter the effect of increased oxidative stress induced by aluminium exposure. We observed that SOD and GPx levels were reduced when the extract was administered alone or together with AS. CAT protects the cells from the accumulation of hydrogen peroxide by converting it to form water and oxygen or by using it as an oxidant which works as a peroxidase [21]. Other authors have suggested that exposure to aluminium was followed by a decrease in the activities of main antioxidant SOD and G-Px in blood (not supported by our findings) and also a decrease in blood CAT activity (which is in accordance with our findings) $[22,23]$.

As a response of oxygen species, a great diversity of aldehydes are formed in biological system that oxidize polyunsaturated fatty acids, and lead to lipid peroxidation. These metabolites lower the body defense system especially by the disturbance of SOD [24]. Regarding the lipid peroxidation, we observed a rise of TBARS levels as consequence of AS exposure, these levels were recovered after extract administration. Elevation of TBARS concentration is due to increased peroxidation of lipids in plasma membranes and is an indicator of oxidative stress [25]. Raise of TBARS could be due to the excessive oxidative damage induced by aluminium exposure. The increase of TBARS in plasma was also noted in a study of Sallam et al. [26] in rabbits exposed to $34 \mathrm{mg} / \mathrm{kg}$ b.w. aluminium chloride, and when it was used an antioxidant (ascorbic acid), the levels of TBARS were restored. The same dynamics of TBARS and $\mathrm{GSH}$ was recorded in a study of Turgut et al.
[15] in serum and liver of mice exposed to 300 $\mathrm{mg} / \mathrm{kg}$ b.w. AS. They observed that TBARS and GSH levels were recovered by administration of a well known antioxidant - vitamin $\mathrm{E}$.

Flavonoids have been shown to alleviate the oxidative stress by increasing the endogenous antioxidant status, protecting cells against free radicals damage by increasing resistance to oxidative stress [27]. S. tectorum contains flavonoids such as kaempferol $[5,6]$. Blazovics et al. [28] emphasized that the active compound of Sempervivum tectorum extract were able to influence the changed cellular redox status in mucosa of all parts of the intestinal tract in experimental bowel disease and pointed out the protective effect of natural polyphenols and flavonoids of $S$. tectorum in thus disease. Kéry et al. [29] noted that S. tectorum extract exhibits a strong inhibition of chemiluminescence, indicating a non-specific free radical scavenging activity. The extract had true superoxide scavenger activity in all free systems and this suggest that it may also act as a direct scavenger of superoxide anions [29].

Regarding the blood Al level, in the present study we observed that it was significantly increased by AS exposure and decreased in presence of the extract. The significant reduction of Al levels by S. tectorum a.e. only in $\mathrm{Al}+\mathrm{St}$ group can be due to the tanin content of this plant [30], the tanins reducing the $\mathrm{Al}$ absorption by precipitation in digestive tract. Administration of S. tectorum one month after AS administration was stopped had not the same effect on Al level, which was not significantly lower than in $\mathrm{Al}$ group and was significantly higher than in $\mathrm{Al}+\mathrm{St}$ group. Our results were in accordance with Szentmihályi et al. [31] which observed a significant reduction of Al level in liver of hyperlipidemic rats folowing $S$. tectorum extract administration due to elevation of Al excretion.

\section{CONCLUSION}

The results of our study indicate that aluminium exposure leads to oxidative stress due to the production of free radicals, increased lipid peroxidation and decreased catalase activity. The aqueous extract of $S$. tectorum, due to its good antioxidant properties, protects against the free radicals produced by aluminium exposure.

\section{ACKNOWLEDGEMENT}

This work was carried out as part of the project, "Postdoctoral School of Agriculture and Veterinary Medicine", POSDRU/89/1.5/S/62371, co-financed by the European Social Fund 
through the Sectorial Operational Programme for the Human Resources Development 2007-2013.

\section{REFERENCES}

1. Penso G. Index Plantarum Medicinalium. OEMF Milano; 1982; $p 625$

2. Abram V, Donko M. Tentative identification of polyphenols in Sempervivum tectorum and assessment of the antimicrobial activity of Sempervivum L. J Agric Food Chem 1999; 47: 485489.

3. Kekesi G, Dobos I, Benedek G, Horvath G. Antinociceptive activity of Sempervivum tectorum L. extract in rats. Phytother Res 2003;17(9): 10321036.

4. Blázovics A, Fehér E, Kéry A, Petri G, Fehér J. Liver protecting and lipid lowering effect of Sempervivum tectorum. Phytother Res 1992; 7: 98-100.

5. Blázovics A, Pronai L, Kéry A, Petri G, Fehér J. Natural antioxidant from Sempervivum tectorum. Phytother Res 1992; 7: 95-97.

6. Alberti A, Blazics B, Kery A. Evaluation of Sempervivum tectorum L. Flavonoids by LC and LC-MS. Cromatographia 2008; 68: 107-111.

7. European Commission [homepage on the internet] Directive 2010/63/EU on the protection of animals used for scientific purposes [cited 2013 Jan 16]. Available

from: http://ec.europa.eu/environment/chemicals/lab_ani mals/legislation_en.htm.

8. Alupului A, Calinescu I, Lavric V. Ultrasonic vs. microwave extraction intensification of active principles from medicinal plants. DOI: 10.3303/ACOS0909001, AIDIC Conference Seriesv2009; 2009; 9: 1-8.

9. Gitelman HJ, Alderman FR. Electrothermal Atomic Absorption Spectrometric Determination of Aluminium: Elimination of Serum Matrix Effects. Clin Chem 1989; 35: 1517-1519.

10. Beutler E, Duron O, Kelly BM. Improved method for the determination of blood glutathione. J Lab Clin Med 1963; 61: 882-888.

11. Paglia DE, Valentine $W N$. Studies on the quantitative and qualitative characterization of erythrocyte glutathione peroxidase. Lab Clin Med 1967; 70: 158-169.

12. Beutler E. Red Cell Metabolism. A manual of Biochemical Methods, 2nd edn. New York: Grune \& Stratton; 1975; pp 69-71.

13. Sinha KA. Colorimetric assay of catalase. Anal Biochem 1972; 47: 389-394.

14. Beuchamp C, Fridovich I. Superoxide dismutase: improved assays and assay applicable to acrylamide gels. Anal Biochem 1971; 44: 276-287.

15. Turgut G, Enli Y, Kaptanoglu B, Turgut S, Genec O. Changes in the levels of MDA and GSH in mice serum, liver and spleen after aluminium administration. Eastern J Med 2006; 11: 7-12.

16. Ward RJ, Zhang $Y$, Crichton RR. Aluminium toxicity and iron homeostasis. J Inorg Biochem 2001; 87: 9-14.
17. Forman H.J.; Bovies A. Superoxide radical and hydrogen peroxide in mitocondria. In: Pryor WA, Ed. Free Radicals in Biology and Medicine. New York: Acad Press; 1982; pp 65-92.

18. De Zwart LL, Meerman JHN, Commandeur JNM, Vermeulen NPE. Biomarkers of free radical damage applications in experimental animals and in humans. Free Rad Biol Med 1999; 26: 202-226.

19. Zatta $P$, Lain E, Cagnolini C. Effect of aluminium on activity of kreb's cycle enzymes and glutamate dehydrogenase in rat brain homogenate. Eur $J$ Biochem 2000; 267: 3049-3055.

20. Chandra $R$, Aneja $R$, Rewal $C$, Konduri $R$, Dass $K$, Agarwal S. An opium alkaloid-papaverine ameliorates ethanol induced hepatotoxicity: diminution of oxidative stress. Indian $\mathrm{J}$ Clin Biochem 2000; 15: 155-160.

21. Lenzi A, Cualosso F, Gandini L, Lombardo F, Dondero F. Placebo controlled double-blind cross over trial glutathione therapy, in male infertility. Human Reprod 1993; 8: 1657-1662.

22. Yousef MI. Aluminium-induced changes in hematobiochemical parameters, lipid peroxidation and enzyme activities of male rabbits: protective role of ascorbic acid. Toxicology 2004; 199: 47-57.

23. Geyikoglu F, Turkez $H$, Keles MS. The role of fruit juices in the prevention of aluminium sulphate toxicity in human blood in vitro. Fresenius Environ Bul 2005; 14: 878-883.

24. Esterbauer $H$, Schaur RJ, Zollner $H$. Chemistry and biochemistry of 4-hydroxynonenal, malonaldehyde and related aldehydes. Free Rad Biol Med 1991; 11: 81-128.

25. Kesavulu MM, Rao BK, Giri R, Vijya JS, Subramanyam $A C H$. Lipid peroxidation and antioxidant enzymes status in type 2 diabetics with coronary heart disease. Diabetes Res Clin Prac 2001; 53: 33-39.

26. Sallam SMA, Nasser MEA, Yousef MSH, El-Morsy AM, Mahmoud SAS, Yousef MI. Influence of aluminium chloride and ascorbic acid on performance, digestibility, caecal microbial activity and biochemical parameters of rabbits. Res J Agric Biol Sci 2005; 1: 10-16.

27. Perez $D$, Strobel $P$, Foncea $R$. Wine, diet, antioxidant defense and oxidative damage. Ann NY Acad Sci 2002; 957: 136-145.

28. Blázovics $A$, Lugasi $A$, Szentmihályi $K$, Kéry $A$. Reducing power of the natural polyphenols of Sempervivum tectorum in vitro and in vivo. Acta Biol Szegediensis 2003; 47: 99-102.

29. Kéry $A$, Balázs $A$, Kursinszki L, Apáti $P$, Szőke $E$, Blazovics A, Hagymasi K, Nagy EM. Radical scavanger and antioxidant activities of selected medicinal plants. Proc Int Conf on MAP. Eds. J. Bernath et al., Acta Hort ISHS 2003; 597: 177-184.

30. Bunny S. The illustrated encyclopedia of herbs: Their Medicinal and Culinary Uses. London: Chancellor press; 1993; pp 320.

31. Szentmihályi K, Fehér E, Vinkler $P$, Kéry A, Blázovics $A$. Metabolic alterations of toxic and nonessential elements by the treatment of Sempervivum tectorum extract in a hyperlipidemic rat model. Toxicol Path 2004; 32: 50-57. 